\title{
Influence of the Operating and Geometric Characteristics of a Bottom-hinged Flap Gate on the Discharge Coefficient of a Side Weir
}

\author{
Matej Müller1,* - Gorazd Novak ${ }^{2}$ - Franc Steinman ${ }^{3}$ - Gašper Rak ${ }^{3}$ - Tom Bajcar ${ }^{4}$ \\ 1 DHD Ltd, Digital Hydrodynamics, Slovenia \\ 2 Hidroinštitut, Institute for Hydraulic Research, Slovenia \\ 3 University of Ljubljana, Faculty for Civil and Geodetic Engineering, Slovenia \\ 4 University of Ljubljana, Faculty of Mechanical Engineering, Slovenia
}

\begin{abstract}
Bottom-hinged flap gates on side weirs are often used for the regulation of flow diversion in case of water abstraction for a variety of needs. In this study, a new equation for the discharge coefficient of a bottom-hinged flap gate on a side weir was proposed on the basis of discharge measurements. The equation was divided into two parts. The first part covers the impact of the sharp-crested side weir and the second the influence of the position and the width of the flap gate. In this manner, the discharge coefficient can be calculated with other authors' equations for a sharp-crested side weir, which then must be multiplied by the new proposed coefficient. Very good agreement was found between the obtained discharge coefficients and the one calculated with the proposed equation. Furthermore, the results were compared with the equations of other authors for the discharge coefficients of sharp-and broad crested side weirs. The agreement was found to be very good. Additionally, measurements of water levels along the edge of the flap gate and measurements of the velocity field were carried out with a computer-aided visualization method. From these measurements, it was possible to show that the contraction of the water jet varies with the gate-opening angle. It was also found that the side weir with a flap gate has the most favorable hydrodynamic shape around the gate-opening angle of $33^{\circ}$, where the discharge coefficient reaches its maximum.
\end{abstract}

Keywords: side weir, discharge coefficient, flap gate, overflow gate, visualization method

Highlights

- A new coefficient is proposed for the correction of the discharge coefficient of a sharp-crested side weir due to the opening gate angle of a bottom-hinged flap gate on the side weir.

- $\quad$ Contraction of the water jet and the discharge coefficient of a side weir with a flap gate are dependent on the gate-opening angle of the flap gate on a side weir.

- $\quad$ The side weir with a flap gate has the most favorable hydrodynamic shape around the gate-opening angle of $33^{\circ}$, where the discharge coefficient reaches its maximum.

- The discharge coefficient of a flap gate on a side weir has its minimum at the gate-opening angle of $0^{\circ}$, where it can be considered as a broad-crested side weir.

\section{O INTRODUCTION}

Side weirs are structures used for flow diversion in case of water abstraction for a variety of needs such as irrigation or for flood water diversion. The latter structures are also known as flood overflows and have proven to be highly useful for the diversion of flood water in wastewater treatment plants as well as for the diversion of water from river channels, for example, when excess water has to be diverted from a river channel to a retention area.

For the proper design of such structures, it is important to know the flow capacity of side weirs, which has already been investigated by various authors. If we define $d Q$ as the flow through an infinitely small stripe ds along the side weir, the general equation for the specific flow over the side weir can be written as follows [1]:

$$
q_{s}=-\frac{d Q}{d s}=\frac{2}{3} \sqrt{2 g} C_{d}(h-p)^{3 / 2},
$$

where $(h-p)$ represents the overflow height over the side weir, $g$ represents the gravitational acceleration, and $C_{d}$ is an empirical coefficient. Several equations have been proposed for the calculation of the coefficient $C_{d}$ for the sharp-crested side weir and for the broad-crested weir. Most of the authors have considered the impact of the inflow Froude number in their equation [2] and [3], some have also considered the impact of the overflow height [4] and [5], but only a few have taken into account the impact of the length of the side weir. The impact of the width of a broadcrested side weir has also been investigated [6] and [7]. Fig. 1 shows the geometric and hydraulic parameters 
that have been proven to have the greatest impact on the coefficient $C_{d}$ [2].

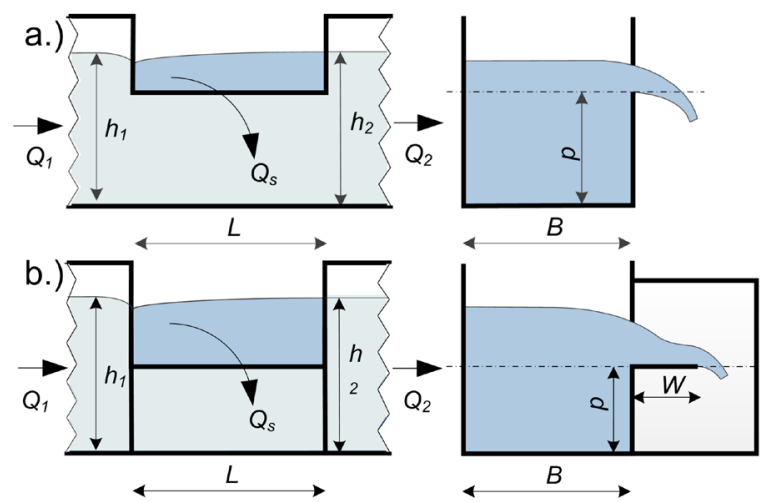

Fig. 1. Sketch of a) a sharp-crested rectangular side weir, and b) a broad-crested side weir

In Fig. $1, h_{1}$ represents the water level of the approaching flow in the main channel, $h_{2}$ the water level of the outflow in the main channel downstream of the side weir, $W$ the width of the flap gate or of the broad-crested side weir, $B$ the width of the main channel, $L$ the length of the side weir, $Q_{1}$ the discharge of the approaching flow in the main channel, $Q_{2}$ the discharge of the outflow in the main channel downstream of the side weir, and $Q_{s}$ the discharge over the side weir.

The need for the regulation of the lateral discharge over the side weir often appears, for example, with the regulation of the water level in the reservoir in the emergence of a flood wave. Therefore, bottom-hinged flap gates are often used on side weir structures to regulate the amount of the lateral discharge over the side weir at different reservoir water levels.

Good knowledge about the discharge capacity of such structures is necessary for the appropriate design and operation of flap gates. Several hydraulic analyses of such gates on weirs have been made by various authors [8] and [9], although available studies of the discharge capacity of flap gates are virtually non-existent. Furthermore, the hydraulic conditions at such structures lack deep analyses, for example of the three-dimensional velocity field. In this paper, a new equation for the coefficient $C_{d}$ of a flap gate on a side weir is proposed; in addition, measurements of the velocity field in the horizontal plane have been made to explain the obtained dependence of the $C_{d}$ from the gate-opening angle $\varphi$. Fig. 2 shows the characteristic parameters of the flap gate on the side weir used in this study. $W$ denotes the width of the flap gate and $\varphi$ the gate-opening angle.

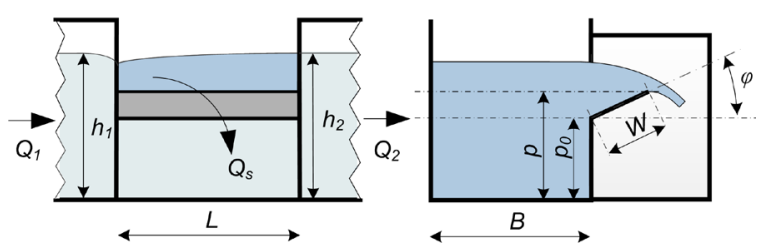

Fig. 2. Sketch of a rectangular side weir with a flat bottom - hinged flap gate

\section{METHODS}

Within the experimental work, discharge, water surface and velocity field measurements were performed. The discharge measurements were performed with the help of a triangular Thomson weir on the upstream end of the model (inflow of water into the model) and a rectangular weir that was placed inside of the channel, on the downstream end of the model (outflow of water out of the main channel). Since such a weir for the measurement of discharges, should be wider than 0.3 $\mathrm{m}$, according to the ISO standard [10], a rating curve of the weir was obtained with the help of the upstream Thomson weir (which was in accordance with the ISO standard) and with the side weir closed. It was found that the correlation between the obtained rating curve and the one according to the ISO standard is very good, since the maximum difference in flow rates does not exceed the value of $1.4 \%$ (for spill heights greater than $3.5 \mathrm{~cm}$, for which the measurements were conducted).

In addition to the discharge measurements, the upstream water levels were also measured to determine a new equation for $C_{d}$. The water levels were measured with a point gauge of $0.1 \mathrm{~mm}$ precision. Furthermore, measurements of the velocity field in a horizontal plane located just above the edge of the flap gate were carried out. The measurements were made with the computer-aided visualization method based on the advection-diffusion equation. This method is implemented in ADMflow software, developed jointly by University of Ljubljana, Faculty of Mechanical Engineering and Abelium [11].

The method has been verified with a number of cases; it has already been used for the measurements of the velocity fields of a free surface flow specific for a case of a side weir. It was found that the most suitable tracer for the measurements in such cases are hydrogen bubbles, which can be produced with galvanization [12]. It has been shown that the uncertainty of the method is $\pm 5 \%$ [11]. 


\section{EXPERIMENTAL SET-UP}

A physical model of the side weir with a bottomhinged sharp edged flat flap gate was constructed and placed in a $6 \mathrm{~m}$ long rectangular channel with the width of $0.2 \mathrm{~m}$. The flap gate was hinged on the sharpcrested side weir and supported with a threaded metal rod, which was then used to fine-tune the position of the flap gate (angle $\varphi$ ). A $0.25 \mathrm{~mm}$ thick copper wire was placed approximately $0.15 \mathrm{~m}$ upstream of the upstream edge of the side weir. The wire was attached to a specially designed fork, which was constructed out of a $2 \mathrm{~mm}$ thick electrically isolated wire. Both the thin wire and the fork were placed at an appropriate distance from the side weir; in this way the water flow in the area of the side weir was not disturbed. The thin copper wire could then be adjusted to the height at which the velocity field was measured at that particular time (the height position of the wire was adjusted to the height of the illuminated plane). At the same location (about $0.15 \mathrm{~m}$ upstream of the upstream edge of the side weir), a copper plate of negligible thickness $(<1 \mathrm{~mm})$ was placed on the bottom of the channel. The copper wire and the plate were connected to a power supply; in this way, a galvanization process started and hydrogen bubbles were produced, which served as a tracer.

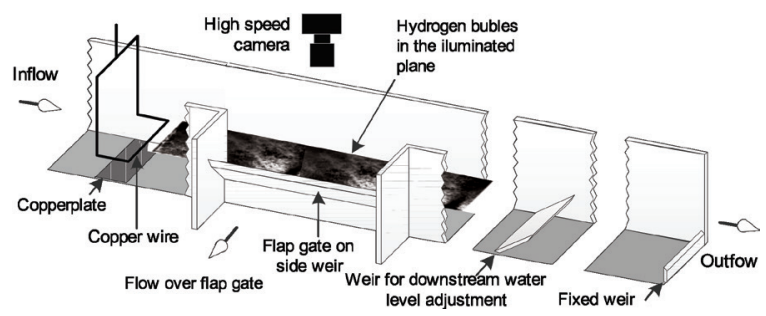

Fig. 3. A sketch of the established physical model and the measurement apparatus

The velocities were measured in the illuminated plane, $5 \mathrm{~mm}$ above the overflow edge of the gate. A height-adjustable weir was placed in the main channel about $1.5 \mathrm{~m}$ downstream of the downstream edge of the side weir, which served for the regulation of the downstream water in the main channel. The position of this weir influenced the upstream conditions and was required to obtain a variety of different Froude numbers and water levels, and thus affected the size of the lateral outflow over the side weir. In actuality, such a regulation would be represented with a gated weir in the river channel.

The fact that the impact of the surface tension is negligible at such model dimensions and that the main channel was already shown in previous studies [12], in which the measurements of the hydraulic conditions at a side weir with a similar length as used in this study made in a $150 \mathrm{~mm}$ wide channel were additionally verified with the measurements made in a wider channel $(0.5 \mathrm{~m})$ with a longer side weir. The research showed a good correlation between the measurements in the narrow and wider channel.

In this study, various lengths $L$ of the side weir $(0.15 \mathrm{~m}, 0.2 \mathrm{~m}$ and $0.25 \mathrm{~m})$ and various heights of the weir $p(0.05 \mathrm{~m}, 0.075 \mathrm{~m}$ and $0.1 \mathrm{~m})$ were considered. Furthermore, all lateral discharge measurements were made for different upstream Froude numbers $F_{1}(0.1$ to 0.41$)$ and different overflow heights $h_{1}-p(0.03 \mathrm{~m}$ to $0.1 \mathrm{~m}$ ), in which both were varied randomly. In all described variants, 7 different positions of the gate (different $\varphi$ ) were considered $\left(0^{\circ}, 10^{\circ}, 20^{\circ}, 33^{\circ}, 45^{\circ}\right.$, $70^{\circ}$ and $90^{\circ}$ ).

A total of 380 measurements with different variants of the above-described parameters were carried out. In every measurement, the inflow and outflow discharges as well as the upstream and downstream water levels were obtained.

To confirm and explain the resulting dependence of $C_{\varphi}$ from $\varphi$, additional velocity measurements were carried out. In order to investigate this dependence, all hydraulic parameters were fixed for all the additional measured variants. At all 7 variants, $F_{1}$ and $h_{1}-p$ and the geometric properties $(L, B, p)$ remained the same, only $\varphi$ was varied $\left(0^{\circ}, 10^{\circ}, 20^{\circ}, 33^{\circ}, 45^{\circ}, 70^{\circ}\right.$, and $90^{\circ}$ ). In addition to the velocity measurements in the horizontal plane, the upstream and downstream water levels and the water levels along the edge of the flap gate were measured for all 7 variants.

\section{RESULTS}

The analysis of the discharge coefficient $C_{d}$ of the flap gate on a side weir has shown that $C_{d}$ is highly dependent of the opening gate angle $\varphi$. The approximate trend of the variation of $C_{d}$ with $\varphi$ can be recognized if all the measured $C_{d}$ against $\varphi$ are placed in a graph (Fig. 4).

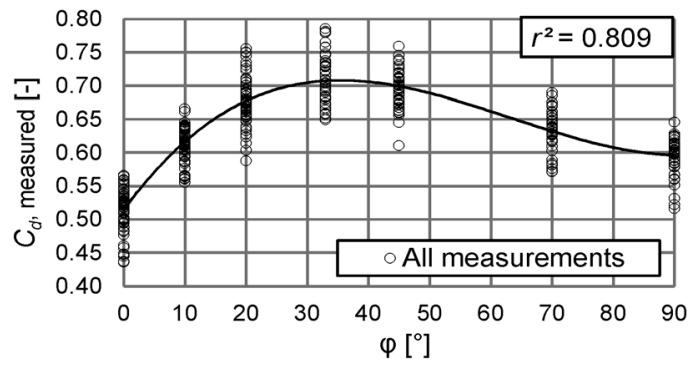

Fig. 4. From the measurements obtained $C_{d}$ in dependence of $\varphi$ 
The trend approximately follows a third-degree polynomial function. In this case, the correlation factor $r^{2}$ is equal to 0.809 . The fact that this trend follows a polynomial function was already shown [8] and [9]; however, their studies were made for flap gates on the weir that were placed perpendicular to the water flow and not on the side weir. Fig. 4 also shows the range of $C_{d}$ values at each $\varphi$, which is between $10 \%$ and $15 \%$. This range is the result of other influential hydraulic parameters of the water flow, such as $F_{1}$ and $h_{1}$, and other influential geometric parameters, such as $L$ and $p$. All of these parameters were also considered in the new equation for $C_{d}$ of the flap gate on a side weir.

\subsection{The New Equation for $C_{d}$}

\subsubsection{Equation Derivation}

It was already shown that the $\mathrm{Cd}$ is mostly affected by the following ratios [2]:

$$
C_{d}=f\left(h_{1} / p, L / B, F\right) .
$$

For the equation of $C_{d}$, a function was chosen in which the ratios from Eq. (2) were considered as the products of several power functions. Similarly, it was already shown that the $C_{d}$ of a broad-crested side weir is, in addition to those already mentioned ratios from Eq. (2), also affected by the ratio [7]:

$$
C_{d}=f\left(h_{1}-p / W\right) .
$$

Because of the finding that the $C_{d}$ in the case of a flap gate on a side weir is also affected by the value of the opening gate angle $\varphi$ (Fig. 4), the latter was also included in the new equation as a polynomial function. A side weir with a flat, bottom-hinged flap gate can be considered to be a sharp-crested side weir without a gate, when the gate is fully closed (i.e. when $\varphi=$ $\left.90^{\circ}\right)$. Therefore, the new equation for $C_{d}$ was divided into two parts. In the first part $\left(C_{d 0}\right)$, the influence of the ratios of the parameters from the Eq. (2) were captured, and in the second part $\left(C_{\varphi}\right)$ the influence of $\varphi$ and the ratios from Eq. (3) were captured. The divided equation reads:

$$
C_{d}=C_{d 0} \cdot C \varphi,
$$

where $C_{d 0}$ denotes the discharge coefficient of the sharp-crested side weir and $C_{\varphi}$ denotes the influence of the flap gate.

Before the new equation was developed, an analysis of the dependence of $C_{d}$ from the parameters in Eq. (3) was conducted. For this purpose, trend lines were produced, which are shown in Fig. 5.
It was found that the dependence of $C_{d}$ on $\left(h_{1}-p / W\right)$ is relative to $\varphi$, as the trend line in Fig. 4 for $\varphi=0^{\circ}$ indicates a downward trend, while the trend line for $\varphi=33^{\circ}$ indicates an upward trend. The downward trend at broad-crested weirs has already been shown by other authors ([6] and [7]), while the upward trend at $\varphi=33^{\circ}$ is quite logical, since the effect of the gate width $W$ decreases with the increase of the overflow height $\left(h_{1}-p\right)$ and is at some point negligible (at $W /\left(h_{1}-p\right)<<1$ ). The trend line for $\varphi=90^{\circ}$ is approximately horizontal, as in this case this ratio has no effect on the $C_{d}$. The different trends of $C_{d}$ in dependence on the ratio $W /\left(h_{1}-p\right)$ at different values of $\varphi$ were captured in the new equation for $C_{d}$ with an additional exponent in $C_{\varphi}$.

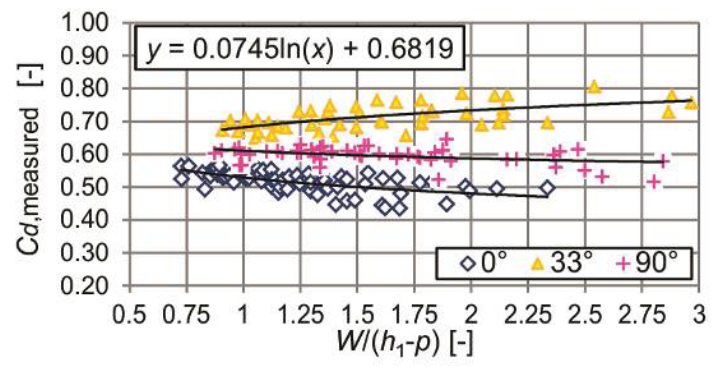

Fig. 5. Measured $C_{d}$ in dependence of the ratio $W /\left(h_{1}-p\right)$

A similar equation was already produced [6] for the broad-crested weir, where the ratio $W /\left(h_{1}-p\right)$ was used as an exponent. However, in our case a logarithmic function was used for the additional exponent instead of a power function, as it was found to suit better the measured data, as well as such a function is quite logical, because it causes the coefficient $C_{d}$ to stabilize from a certain value of the ratio $W /\left(h_{1}-p\right)$ on. The proposed form of the new equation for the $C_{d}$ of a bottom-hinged flap gate on a side weir is as follows:

$$
\begin{aligned}
& C_{d}=a\left(\frac{h_{1}}{p}\right)^{b}\left(F_{1}\right)^{c}\left(\frac{L}{B}\right)^{d} . \\
& \cdot\left(f \cdot \phi^{j}+g \cdot \phi^{k}+h \cdot \phi^{l}+i\right)^{m \cdot \ln \left(W /\left(h_{1}-p\right)\right)+n},
\end{aligned}
$$

where $\varphi$ is given in radians and the coefficients $a, b$, $c, d, f, g, h, i, j, k, l, m, n$ represent unknowns, which were determined on the basis of all 380 measurements and with the use of the generalized reduced gradient (GRG) method. Table 1 shows the obtained values for all unknowns.

With the parameters $a$ to $n$, the correlation factor between the values that were obtained from the measurements and the values that were calculated from Eq. (5) is $C_{d}$, is $r^{2}=0.856$. 
Table 1. Values of the unknowns in Eq. (5)

\begin{tabular}{ccccccc}
\hline \multicolumn{2}{l}{ a) Unknowns a to $g$} & \multicolumn{1}{c}{} \\
\hline$A$ & $b$ & $c$ & $d$ & $f$ & $g$ \\
\hline 0.482 & 0.023 & -0.080 & 0.150 & 0.3086 & -1.7499 \\
\hline \multicolumn{7}{l}{ b) Unknowns $h$ to $n$} \\
\hline$h$ & $i$ & $j$ & $k$ & $l$ & $m$ & $n$ \\
\hline 1.5359 & 0.9423 & 2.0996 & 1.4039 & 1.1314 & 2.7 & 2.0 \\
\hline
\end{tabular}

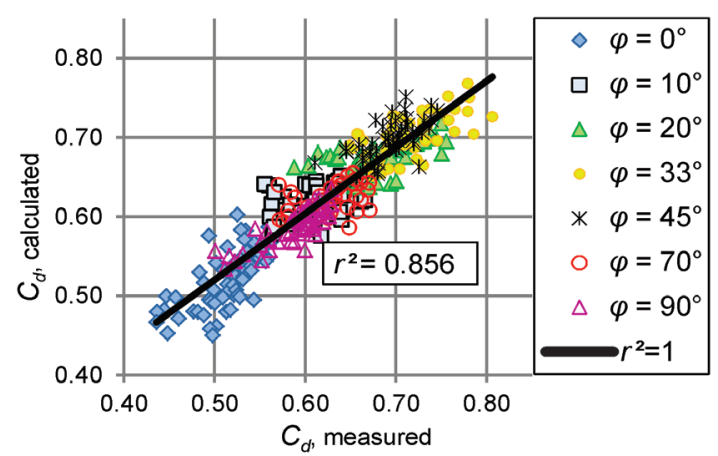

Fig. 6. Correlation between the measured and the calculated values of $C_{d}$

Furthermore, the average difference between these values does not exceed $3.2 \%$, the maximal difference does not exceed $13.9 \%$, and the standard deviation is 0.06 , which is similay to what other authors found in their studies [2]. Fig. 6 shows the correlation between the measured and the calculated values of $C_{d}$.

According to Eq. (3), Eq. (4) can be divided into two parts:

$$
\begin{gathered}
C_{d 0}=a\left(\frac{h_{1}}{p}\right)^{b}\left(F_{1}\right)^{c}\left(\frac{L}{B}\right)^{d}, \\
C_{\phi}=\left(f \cdot \phi^{j}+g \cdot \phi^{k}+h \cdot \phi^{l}+i\right)^{m \cdot \ln \left(W /\left(h_{1}-p\right)\right)+n},
\end{gathered}
$$

when the value $\varphi$ is $1.5708 \mathrm{rad}$, which is equivalent to the angle $90^{\circ}$, Eq. (7) reduces to the value of 1 , regardless to the values $W, h_{1}$ or $p$. Thus, Eq. (3) reduces itself to $C_{d}=C_{d 0}$, which is entirely logical, as the side weir with a flap gate in a fully closed gate position (i.e. at $\varphi=90^{\circ}$ ) is equivalent to a sharpcrested side weir and the ratio $W /\left(h_{1}-p\right)$ does not have any impact on the value of $C_{d}$.

\subsubsection{Verification Using Other Experimental Data for Sharp-Crested Weirs}

The comparison of our measurements of $C_{d}$ for the gate angle $\varphi=90^{\circ}$ with the calculated values from equations developed from other authors showed very good agreement. Furthermore, the comparison of our measurements of $C_{d}$ for the gate angle $\varphi=90^{\circ}$ with those calculated after Eq. (6) also showed very good agreement, as the average difference does not exceed $2.8 \%$. The best agreement of our measurements with the equations from other authors was found by the comparison with the study from [4], in which the side walls in the side channel were also considered, as was done in our case. Furthermore, the measured values are in good agreement with the calculated values according to the equation in [13], where the average difference does not exceed $3.7 \%$ and the maximum difference $8 \%$. The calculated values from the equations of other authors and our measured values of $C_{d}$ are mainly located within the $10 \%$ range [14] and [15]; however, it must be noted that other authors did not consider the side walls in the side channel. The agreement of our measured values of $C_{d}$ and the calculated values by the equation in [5] and [16] is out of the $10 \%$ range. However, it should be noted that the trends are very similar. Furthermore, the values calculated from the equations of other authors differ; for example, the mean difference between [5] and [15] is $35 \%$, and the difference between [3] and [5] is more than $50 \%$ (Fig. 7).

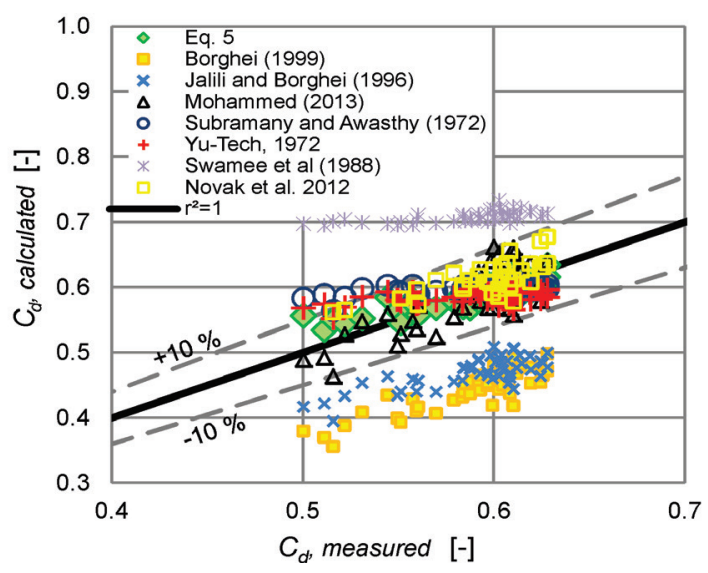

Fig. 7. Comparison of the measured $C_{d}$ at $\varphi=90^{\circ}$ and calculated from the Eq. (6) and from equations of other authors

\subsubsection{Verification Using Other Experimental Data for Broad-Crested Weirs}

As already mentioned, the side weir with the position of the flap gate at $\varphi=0^{\circ}$ can be considered to be a broad-crested side weir, for which the width of the gate $W$ represents the width of the broad-crested weir. Therefore, at values of $\varphi=0^{\circ}$, Eq. (5) reduces 
to an equation for a broad-crested side weir, and the coefficient $C_{\varphi}$ is in this case equal to:

$$
C_{\phi}\left(\phi=0^{\circ}\right)=C_{W}=i^{m \cdot \ln \left(W /\left(h_{1}-p\right)\right)+n} .
$$

where $C_{W}$ denotes the correction factor for $C_{d}$ for the case of a broad-crested side weir. The comparison of the calculated coefficients $C_{W}$ after Eq. (8) for the measured variants where the gate was fully opened $\left(\varphi=0^{\circ}\right)$ with the calculated values after the equations for a broad-crested weir from other authors, showed good agreement. From the correlation of the values calculated with Eq. (8) and values calculated after the equation in [7], a correlation factor $r^{2}$ of 0.97 was obtained and from the correlation with [6] a value of $r^{2}=0.95$. Furthermore, in the first case, the average difference is less than $1.3 \%$ and in the second, even lower than $1 \%$, while the maximum difference does not exceed $5 \%$ in either one. It should be noted that the equation in [7] was made for a broad-crested side weir, and the equation in [6] was made for a broadcrested weir. Fig. 8 shows the correlation between the calculated values according to Eq. (8) and according to other authors for all measured variants where the gate was fully opened $\left(\varphi=0^{\circ}\right)$.

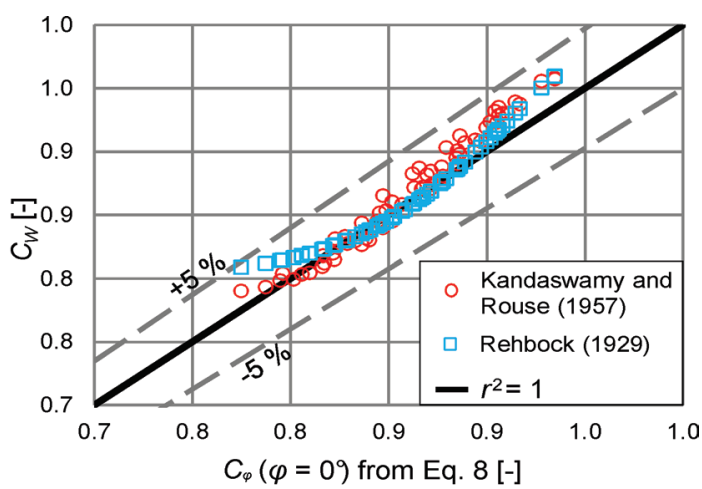

Fig. 8. Correlation between $C_{\varphi}$ according to the Eq. (8) and the calculated $C_{W}$ according to other authors for all measurements with the flap gate fully opened $\left(\varphi=0^{\circ}\right)$

\subsubsection{Verification Using Other Experimental Data for Bottom-Hinged Flap Gates on Weirs}

Fig. 9 shows the dependence of $C_{\varphi}$ on $\varphi$ according to Eq. (7) for different ratios $W /\left(h_{1}-p\right)$ which vary from 0.6 to 2.8 , which is for the range for which the measurements were conducted. It can be seen that according to Eq. (7) the trend of $C_{\varphi}$ in dependence of $W /\left(h_{1}-p\right)$ turns at $\varphi=7.5^{\circ}$.

According to Eq. (7), $C_{\varphi}$ is approximately 1 when the $W /\left(h_{1}-p\right)<0.5$ (i.e. in the case when the overflow height $\left(h_{1}-p\right)$ is two times greater than the width of the gate $W$ ). Therefore, in this case, the impact of the flap gate on $C_{d}$ is negligible.

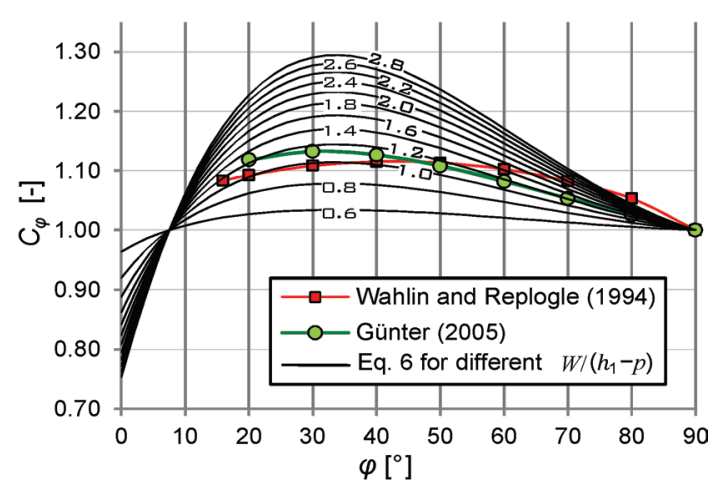

Fig. 9. Dependence of $C_{\varphi}$ on $W /\left(h_{1}-p\right)$ according to the Eq. (7) and the comparison of $C_{\varphi}$ with the equations from other authors

A much greater impact of the flap gate on $C_{d}$ was found to be at higher values of the ratio $W /\left(h_{1}-p\right)$ (i.e. in the case when the overflow height $\left(h_{1}-p\right)$ is smaller than the width of the flap gate $W$ ), where $C_{\varphi}$ reaches a value of 1.3 at the angle $\varphi=33^{\circ}$. Fig. 9 also shows that the calculated values of $C_{\varphi}$ according to Eq. (7) matches very well with the formula stated by Günter in his book about weirs [8]. The agreement of $C_{\varphi}$ according to Eq. (7) and the equation in [9] was found to be less good, but still satisfactory. However, the authors did not consider the impact of the ratio $W /\left(h_{1}-p\right)$ on $C_{\varphi}$; moreover, those studies were made for weirs and not for side weirs.

\subsection{Verification with Additional Measurements}

In order to verify the obtained equation for $C_{\varphi}$, additional measurements were carried out, in which $\left(h_{1}-p\right)$ and $F_{1}$ were fixed for all measured variants and only $\varphi$ was varied for 7 different opening gate angles $\varphi$. In this way, it was possible to assess the effect of $\varphi$ on $C_{\varphi}$ and remove the influence of other parameters. First, the coefficients $C_{d}$ were obtained from the measurements. Then, using the value obtained for $C_{d}$ at the angle of $90^{\circ}$, the coefficients $C_{\varphi}$ were calculated. All geometric and other measured hydraulic parameters from the conducted additional measurements are listed in Table 2.

The agreement of the measured values of $C_{d}$ and the calculated with Eqs. (5) and (7) was found to be good, as the maximum relative difference between them is $4 \%$ for $C_{d}$ and $2.8 \%$ for $C_{\varphi}$.

The calculated $C_{\varphi}$ according to Eq. (7), and the obtained $C_{\varphi}$ from the additional measurements are given in Fig. 10. 
Table 2. Geometric and other measured hydraulic parameters for the additional measurements

\begin{tabular}{cccccccc}
\hline $\begin{array}{c}\varphi \\
{\left[{ }^{\circ}\right]}\end{array}$ & $\begin{array}{c}Q_{l} \\
{[\mathrm{l} / \mathrm{s}]}\end{array}$ & $\begin{array}{c}Q_{s} \\
{[\mathrm{l} / \mathrm{s}]}\end{array}$ & $\begin{array}{c}p_{0} \\
{[\mathrm{~cm}]}\end{array}$ & $\begin{array}{c}h_{1}-p \\
{[\mathrm{~cm}]}\end{array}$ & $\begin{array}{c}\mathrm{L} \\
{[\mathrm{cm}]}\end{array}$ & $\begin{array}{c}\mathrm{B} \\
{[\mathrm{cm}]}\end{array}$ & $\begin{array}{c}F_{1} \\
{[-]}\end{array}$ \\
\hline 0 & 5.92 & 1.9 & 7.5 & 3.54 & 20 & 20 & 0.26 \\
\hline 10 & 6.85 & 2.36 & 7.5 & 3.52 & 20 & 20 & 0.26 \\
\hline 20 & 7.54 & 2.68 & 7.5 & 3.51 & 20 & 20 & 0.26 \\
\hline 33 & 8.77 & 2.83 & 7.5 & 3.54 & 20 & 20 & 0.26 \\
\hline 45 & 9.70 & 2.74 & 7.5 & 3.50 & 20 & 20 & 0.26 \\
\hline 70 & 11.02 & 2.47 & 7.5 & 3.53 & 20 & 20 & 0.26 \\
\hline 90 & 11.40 & 2.42 & 7.5 & 3.68 & 20 & 20 & 0.24 \\
\hline
\end{tabular}

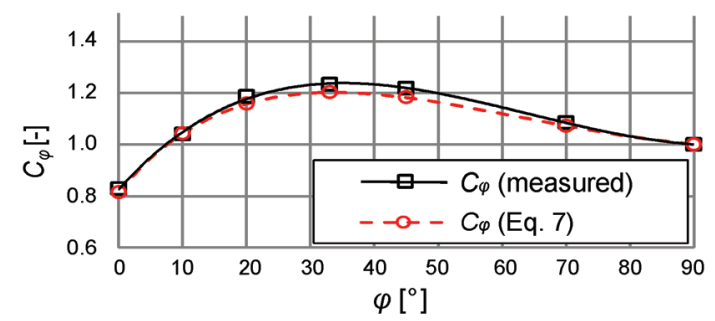

Fig. 10. Comparison of the values obtained from measurements and with the Eq. (7) calculated values of $C_{\varphi}$

From the comparison of the values obtained from the measurements and the values calculated from Eq. (7) for the examples of the additional measured variants, a correlation factor $r^{2}=0.99$ was found. Therefore, we can conclude that Eqs. (5) and (7) give adequate results.

\section{DISCUSSION OF THE OBTAINED $C_{d}$}

\subsection{Water Surface and Flow Area}

The lower values of $C_{\varphi}$ in the case when the flap gate is fully opened can be explained by the fact that such a position is similar to a broad-crested side weir, where the flow rate over the weir is smaller than by sharpcrested side weirs, due to a different contraction of the water jet. By closing the gates (by increasing $\varphi$ ), the contraction of the water jet changes and it becomes much more similar to the water jet that occurs at sharp-crested side weirs. An example of the different contractions of the water jet at sharp- and broadcrested side weirs is shown in Fig. 1. To confirm this hypothesis, the flow area of the cross-section at the edge of the flap gate was obtained from the additional measured variants, where the water levels were measured using a point gauge.

Fig. 11 shows that the flow area $A$, in spite of the same inflow conditions $\left(h_{1}-p\right)$ and $F_{1}$, increases rapidly at angles from $\varphi=0^{\circ}$ to $\varphi=33^{\circ}$ (over $50 \%$ ), while at angles from $\varphi=33^{\circ}$ to $\varphi=90^{\circ}$ it increases only slightly (less than $10 \%$ ).

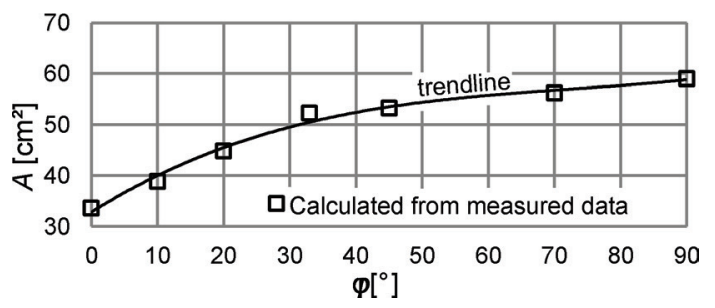

Fig. 11. The flow area in the cross-section at the edge of the flap gate in dependence of $\varphi$, with the same inflow conditions $\left(F_{1}=0.26, h_{1}-p=3.5 \mathrm{~cm}\right)$

\subsection{Velocity Field}

According to the obtained flow areas $A$ at different $\varphi$, shown in Fig. 11, and according to the obtained discharge for this same measured variants $Q_{s}$, the dependence of the average transverse (according to the axis of the main channel) velocities from the opening gate angle $\varphi$ should be obtained from Eq. (9), shown in Fig. 12.

$$
v_{y, q}=Q_{s} / A
$$

In order to confirm the resulting average velocity component $v_{y, q}$ and thus the measured values of $A$ and $Q_{s}$, measurements of the velocity field were carried out with the computer-aided visualization method in the horizontal plane $5 \mathrm{~mm}$ above the overflow edge of the flap gate (this plane is denoted $P$ ), for all 7 additional measured variants.

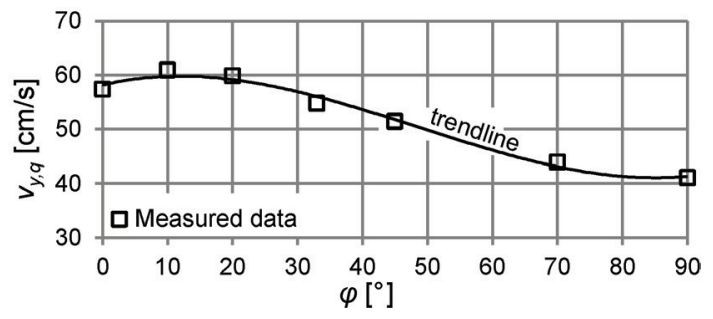

Fig. 12. From Eq. (9) calculated average $y$ velocity components $v_{y, q}$ on the cross-section at the edge of the flap gate in dependence of $\varphi$

It can be seen from Fig. 13 that the measured vectors at $\varphi=33^{\circ}$ (Fig. 13a) are much more perpendicularly oriented to the edge of the flap gate than the vectors for $\varphi=90^{\circ}$ (Fig. 13b). Because of this, the velocity components in the $y$ direction are in general greater in the first two cases. This is in good 
agreement with the velocity distribution seen in Fig. 12.

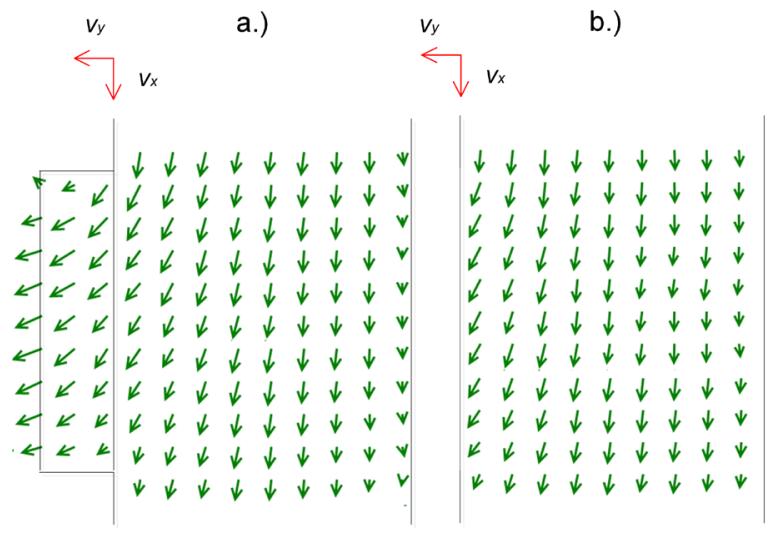

Fig. 13. The measured velocities in the horizontal plane $P$ with the inflow conditions $F_{1}$ and $\left(h_{1}-p\right)$, for a) $\varphi=33^{\circ}$ and b) $\varphi=90^{\circ}$

To support the above-described explanation with quantitative values, both velocity components were therefore spatially averaged over the cross-section of the flow area along the overflow edge of the flap gate. Because the computer-aided visualization method provides instantaneous velocities, the values also had to be time-averaged across a time window of 30 frames, which were captured with a high-frequency camera with a recording rate 300 frames per second. In the horizontal plane $P$, spatially and time-averaged velocities are denoted with $v_{y, P}$

Fig. 14 shows a comparison of the measured velocities $v_{y, P}$ and the velocities $v_{y, q}$, calculated with Eq. (9). It can be seen that the maximal difference between them is about $10 \%$, which is within the range of uncertainty of all used measuring methods, considering that the error of the point gauge, used for the measurement of $A$ and the error due to the interpolation of water levels between the measured points is around $2 \%$, the error of the discharge measurements does not exceed $3 \%$, and the error of the computer-aided visualization method was shown to be around $5 \%$ [11].

It should be noted that for a more precise determination of the averaged $y$ velocity component, velocity measurements in horizontal planes that are higher than the measured plane $P$ would be needed, as most likely the velocity profile at the edge of the flap gate is not constant along the vertical. The biggest impact of the height-distributed velocity profile is most likely to occur at higher $\varphi$, where the height of the water jet at the edge of the flap gate is the greatest. It is precisely at this gate-opening angle where the maximal differences between the measured velocities $v_{y, P}$ and the calculated velocities $v_{y, q}$ appear. However, because the purpose of these measurements in thus study was only to verify the trend of the obtained velocities from Fig. 12, the accuracy of the conducted measurements was completely satisfactory. The correlation between $v_{y, P}$ and $v_{y, q}$ shows a very good agreement, since $r^{2}$ is 0.982 .

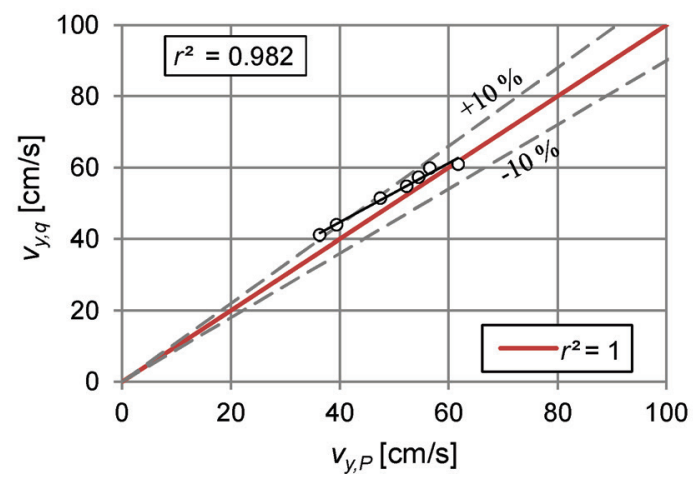

Fig. 14. Comparison of $v_{y, P}$ and $v_{y, q}$

\section{CONCLUSIONS}

In this study, a new equation for the discharge coefficient $C_{d}$ of a bottom-hinged flap gate on a side weir was proposed on the basis of 380 measurements. The equation was divided into two parts: the first part covers the impact of the sharp-crested side weir, while the second part covers the influence of the position $\varphi$ and width $W$ of the flap gate. In this way, the coefficient $C_{d}$ can also be calculated with the help of an equation for a sharp-crested side weir from another author, which than has to be multiplied by the coefficient $C_{\varphi}$ that represents the second part of the proposed equation.

For the verification of the proposed equation for $C_{\varphi}$, additional discharge measurements were carried out with the same inflow conditions, $F_{1}$ and $\left(h_{1}-p\right)$, and different gate-opening angles $\varphi$. The analysis showed very good agreement with the proposed equation.

For all the additionally measured variants, measurements of water levels along the edge of the flap gate and measurements of the velocity field in the horizontal plane $P$, which is located just above the edge of the gate, were carried out with a computeraided visualization method. From these measurements, it was possible to show that the contraction of the water jet and the flow area of the vertical crosssection along the edge of the gate vary with the gateopening angle $\varphi$. The latter has evidently a significant impact on the flow over the side weir with flap gates. 
Furthermore, the measurements of the velocity field helped to explain the obtained dependence of $C_{\varphi}$ from $\varphi$. It was found that the position of the flap gate has a significant impact on the discharge coefficient $C_{d}$, as the hydrodynamic shape of the weir changes with the position of the flap gate. (among others factors). It was also found that the side weir with a flap gate has the most favorable hydrodynamic shape around the gate-opening angle $\varphi=33^{\circ}$, where the coefficient $C_{d}$ reaches its maximum.

The proposed equation will contribute to a better and more accurate design of overflow spillways with flap gate regulation, and it will also contribute to more appropriate operation of such structures, for which it is very important to know the flow capacity at different operating stages. In addition, the results will be very useful for the calibration and verification of two- and three-dimensional numerical models, which have become increasingly used for hydraulic analysis of such structures in recent years [17] and [18].

In this study, a flat flap gate without the impact of the downstream water level in the side channel was investigated. In further research, it would be very useful to analyze the dependence of the discharge coefficient $C_{d}$ from the flap gate shape form (different curvatures) and the height of the downstream water level in the side channel. Furthermore, it would be interesting to compare the obtained results with the results of a numerical model, which in this case would have to be a three-dimensional model with a suitable turbulence model.

\section{ACKNOWLEDGEMENTS}

This work is in part supported by the Slovenian Research Agency (ARRS), grant L2-4270.

\section{REFERENCES}

[1] De Marchi, G. (1934). Essay on the performance of lateral weirs. L'Energia Electrica Milan, vol. 11, no. 11, p. 849-860.

[2] Singh, R., Manivannan, D., Satyanarayana, T. (1994). Discharge coefficient of rectangular side weirs. Journal of Irrigation and Drainage Engineering, vol. 120, no. 4, p. 814819, D0I:10.1061/(ASCE)0733-9437(1994)120:4(814).

[3] Swamee, P.K., Pathak, S.K., Mohan, M., Agrawal, S.K., Ali, M.S. (1994). Subcritical flow over rectangular side weir. Journal of
Irrigation and Drainage Engineering, vol. 120, no. 1, p. $212-$ 217, D0I:10.1061/(ASCE)0733-9437(1994)120:1(212).

[4] Mohammed, A.Y. (2013). Numerical analysis of flow over side weir. Journal of King Saud University - Engineering Sciences, vol. 27, no. 1, p. 37-42, D0l:10.1016/j.jksues.2013.03.004.

[5] Borghei, S., Jalili, M., Ghodsian, M. (1999). Discharge coefficient for sharp-crested side weir in subcritical flow. Journal of Hydraulic Engineering, vol. 125, no. 10, p. 10511056, DOI:10.1061/(ASCE)0733-9429(1999)125:10(1051).

[6] Rehbock, T. (1929). Discussion of "Precise measurements" by Turner K., B. Trans., vol. 93, p. 1143-1162.

[7] Kandaswamy, P.K., Rouse, H. (1957). Characteristics of flow over terminal weirs and sills. Journal of the Hydraulics Division, vol. 83, no. 4, p. 1-13.

[8] Günter, P. (2005). Überfälle und Wehre: Grundlagen und Berechnungsbeispiele. Vieweg Verlag, Wiesbaden.

[9] Wahlin, B.T., Replogle, J.A. (1994). Flow Measurement Using an Overshot Gate, UMA Engineering, Inc., Washington.

[10] ISO 1438:2008(E). (2008). Hydrometry - Open Channel Flow Measurement Using Thin-Plate Weirs. International Organization for Standardization, Geneva.

[11] Bajcar, T., Širok, B., Eberlinc, M. (2009). Quantification of flow kinematics using computer-aided visualization. Strojniški vestnik- - Journal of Mechanical Engineering, vol. 55, no. 4, p. 215-223.

[12] Novak, G., Steinman, F., Müller, M., Bajcar, T. (2012). Study of velocity field at model sideweir using visualization method. Journal of Hydraulic Research, vol. 50, no. 1, 129-133, D0l:10 $.1080 / 00221686.2011 .648766$.

[13] Novak, G., Kozelj, D., Steinman, F., Bajcar, T. (2013). Study of flow at side weir in narrow flume using visualization techniques. Flow Measurement and Instrumentation, vol. 29, no. 3, p. 45-51, D0l:10.1016/j.flowmeasinst.2012.10.008.

[14] Yu-Tech, L. (1972). Discussion: Spatially varied flow over side weir. Journal of the Hydraulics Division, vol. 98, no. 11, p. 2046-2048

[15] Subramanya, K., Awasthy, S.C. (1972). Spatially varied flow over side weirs. Journal of the Hydraulics Division, vol. 98, no. 1, p. 1-10.

[16] Jalili, M.R., Borghei, S.M. (1996). Discussion: Discharge coefficient of rectangular side weir. Journal of Irrigation and Drainage Engineering, vol. 122, no. 2, p. 132, Dol: 10.1061/ (ASCE)0733-9437(1996)122:2(132).

[17] Milési, G., Causse, S. (2014). 3D numerical modeling of a side-channel spillway. Gourbesville, P., Cunge, J., Caignaert, P. (eds.). Advances in Hydroinformatics, Springer Singapore, $p$. 487-498, DOI:10.1007/978-981-4451-42-0_39.

[18] Namaee, R.M., Rostami, M., Jalaledini, S., Habibi, M.A. (2014). 3-dimensional numerical simulation of flow over a broadcrested side weir. Gourbesville, P., Cunge, J., Caignaert, P. (eds.). Advances in Hydroinformatics, Springer Singapore, $p$. 511-523, DOI:10.1007/978-981-4451-42-0_41. 